NBER WORKING PAPER SERIES

IS BAD NEWS ABOUT INFLATION GOOD NEWS FOR THE EXCHANGE RATE?

\author{
Richard Clarida \\ Daniel Waldman \\ Working Paper 13010 \\ http://www.nber.org/papers/w13010 \\ NATIONAL BUREAU OF ECONOMIC RESEARCH \\ 1050 Massachusetts Avenue \\ Cambridge, MA 02138 \\ April 2007
}

We would like to thank John Campbell, Charles Engel, Martin Feldstein, and Vineer Bhansali for sharing their insights on this topic with us. The views expressed herein are those of the author(s) and do not necessarily reflect the views of the National Bureau of Economic Research.

(C) 2007 by Richard Clarida and Daniel Waldman. All rights reserved. Short sections of text, not to exceed two paragraphs, may be quoted without explicit permission provided that full credit, including (c) notice, is given to the source. 
Is Bad News About Inflation Good News for the Exchange Rate?

Richard Clarida and Daniel Waldman

NBER Working Paper No. 13010

April 2007

JEL No. E31,F3,F31

\begin{abstract}
$\underline{\text { ABSTRACT }}$
We show in a simple -- but robust -- theoretical monetary exchange rate model that the sign of the covariance between an inflation surprise and the nominal exchange rate can tell us something about how monetary policy is conducted. Specifically, we show that 'bad news' about inflation -- that it is higher than expected -- can be 'good news' for the nominal exchange rate -- that it appreciates on this news -- if the central bank has an inflation target that it implements with a Taylor Rule. The empirical work in this paper examines point sampled data on inflation announcements and the reaction of nominal exchange rates in 10 minute windows around these announcements for 10 countries and several different inflation measures for the period July 2001 through March 2005. When we pool the data, we do in fact find that bad news about inflation is indeed good news for the nominal exchange rate, that the results are statistically significant, and that the r-square is substantial, in excess of 0.25 for core measures of inflation. We also find significant differences comparing the inflation targeting countries and the two non-inflation targeting countries.
\end{abstract}

Richard Clarida

Columbia University

420 West 118th Street

Room 826, IAB

New York, NY 10027

and NBER

rhc2@columbia.edu

Daniel Waldman

200 East 72nd Street- Apt. 9F

New York, NY 10021

djw74@columbia.edu 


\title{
IS BAD NEWS ABOUT INFLATION GOOD NEWS FOR THE EXCHANGE RATE?
}

\author{
And If So, Can That Tell Us Anything About the Conduct of Monetary \\ Policy?
}

\section{Richard Clarida and Daniel Waldman Columbia University}

Dollar Rises as U.S. Consumer Inflation Accelerates in February March 23, 2005 (Bloomberg) -- The dollar rose against the euro after a measure of inflation accelerated last month, bolstering expectations the Federal Reserve will raise its benchmark interest rate at a faster pace.

\section{Introduction}

The interplay between monetary policy and asset prices is a subject of longstanding interest in financial economics. Often - but not always - the focus is directed at trying to understand how monetary policy, or shocks to policy, impacts asset prices - whether these be the prices of equities, bonds, property, or currencies. Less often, the focus is on how - or should - asset prices influence the conduct of monetary policy. This paper takes a different approach. We ask, can the response of an asset price - in our case the exchange rate - to a non policy shock - in our case a surprise in inflation - tell us something about how monetary policy is conducted?

This paper makes a theoretical point and provides some empirical support for this point. We show in a simple - but robust - theoretical monetary exchange rate model that the sign of the covariance between an inflation surprise and the nominal exchange rate can tell us something about how monetary policy is conducted. Specifically, we show that 'bad news' about inflation - that it is higher 
than expected - can be 'good news' for the nominal exchange rate - that it appreciates on this news - if the central bank has an inflation target that it implements with a Taylor Rule. This result at first seemed surprising to us because our model is one of inflation - not price level - targeting so that in the model a shock to inflation has a permanent effect on the price level. Since PPP holds in the long run of the model, the nominal exchange rate depreciates in the long run to an inflation shock, even though on impact it can appreciate in response to this shock. We show that in a traditional overshooting model in which the central bank sets a growth rate for the money stock, the exchange rate would be expected depreciate in response to an inflation shock.

The empirical work in this paper examines point sampled data on inflation announcements and the reaction of nominal exchange rates in 10 minute windows around these announcements for 10 countries and several different inflation measures for the period July 2001 through March 2005. Eight of the countries in our study are inflation targeters, and two are not. When we pool the data, we do in fact find that bad news about inflation is indeed good news for the nominal exchange rate, that the results are statistically significant, and that the $r$ - square is substantial, in excess of 0.25 for core measures of inflation. We also find significant differences comparing the inflation targeting countries and the two non-inflation targeting countries. For the non-IT countries, there is no significant impact of inflation announcements on the nominal exchange rate, although the estimated sign is indeed in line with our story. For each of the IT countries the sign is as predicted by the theory and quite significant. Finally we 
study two countries, the UK and Norway in which there was a clear regime change during a period when we can obtain data. We study the granting of independence to the Bank of England in 1997 and the shift to formal inflation targeting by Norway in 2001 . For both countries, the correlation between the exchange rate and the inflation surprise before the regime change reveal that 'bad news about inflation was bad news about the exchange rate'. After the regime change, we find that indeed 'bad news about inflation is good news about the exchange rate'.

\section{Optimal Monetary Policy in the Open Economy: Some Results}

Before we proceed further, it will be useful to review some of the results from a model of optimal monetary policy and exchange rate determination in the open economy developed in Clarida-Gali-Gertler (2002). There are two countries, each with staggered price setting and facing 'cost push' shocks that generate inflation inertia. Home and foreign countries produce differentiated traded goods - the terms of trade is a key relative price. International spillovers arise via a marginal cost/optimal labor supply channel, and these impact inflation dynamics via staggered optimal price setting as in Calvo. The paper follows Woodford and derives the central bank welfare function and the optimal monetary policy reaction function in the open economy from taste, technology, and market clearing subject to the Calvo pricing constraint. Solving the model under discretion, there are several results that are relevant to the present discussion. 
First, optimal monetary policy in each open economy can be formulated as a Taylor Rule

$$
i=r r+E \pi_{+1}+b\left(\pi-\pi^{*}\right)
$$

where $\mathrm{i}$ is the nominal interest rate, $r \mathrm{rr}$ is the time varying real interest rate, $\pi$ is inflation, $\pi^{*}$ is the inflation target, and $E$ is the expectations operator. Second, under optimal monetary policy, the Taylor Rule is a function of deep parameters

$$
b=(\sigma+(1-\sigma) \gamma) \xi(1-\rho)>0
$$

where $\sigma$ is the intertemporal elasticity of substitution, $\gamma$ is the share of imports in the consumption basket, $\xi$ is the elasticity of substitution across varieties of intermediate inputs to the production of final output, and $\rho$ is the exogenous persistence in shocks to marginal cost. Third, optimal monetary policy features a flexible exchange rate, but the exchange rate itself does not enter the reaction function. Fourth, openness has its effects through the neutral real interest rate and the slope of the Taylor Rule. Fifth, the nominal exchange rate under optimal policy has a unit root as does the domestic price level and they are co integrated so that PPP holds in the long run.

Clarida-Gali-Gertler (2002) works out in some detail the symmetric, two country Nash equilibrium under central bank discretion. They show that in the symmetric equilibrium, bad news about inflation is good news for the exchange rate. That is, a Phillips curve shock that pushes up actual (and expected) inflation triggers under optimal policy an aggressive rise in nominal and real interest rates that actually causes the nominal exchange rate to appreciate. This is so even 
though in the long run the nominal exchange rate must depreciate in response to an inflation shock.

There is a tension. Using uncovered interest parity and long run PPP we have (normalizing foreign interest rates and log price levels to zero)

$$
e=-\Sigma_{j=0, \infty} E i_{j}+\Sigma_{j=0, \infty} E \pi_{j}+p_{-1}
$$

In the long run, the level of the nominal exchange rate must depreciate in line with PPP in response to an inflation shock. Under an inflation targeting monetary policy of the sort derived by CGG (2002), after its initial jump the nominal exchange rate must be depreciating along the adjustment path (since the home nominal interest rate is above the world interest rate when inflation is above target). However, in response to an inflation shock the domestic price level rises on impact, which will tend to make the exchange rate weaker. In the CGG (2002) theoretical model, optimal monetary policy has the property that the rise in interest rates in response to the monetary policy shock is sufficiently large to deliver the association between an adverse inflation shock and an nominal currency appreciation.

\section{Inflation Shocks in a Dornbusch Style Model}

In a Dornbusch style model with a money growth target, a shock that pushes up inflation will, under plausible circumstances, result in a depreciation of the nominal exchange rate Intuitively, in a Dornbusch model with a money growth target - but one that accommodates to some extent an inflation shock so 
that the price level has a unit root - the long run PPP anchor tends to make the nominal exchange rate and the price level move in the same direction whether or not the shock is to the money supply or to the Phillips curve. The analysis is straightforward.

We begin with a money demand equation

$$
m-p=-\lambda\left(e^{e}-e\right)
$$

where $\lambda$ is the interest semi elasticity of money demand. Next is a standard Phillips curve from this literature augmented with an inflation shock term $\varepsilon$.

$$
p=p_{-1}+\mu+\eta(e-p)+\varepsilon
$$

Next is a money growth equation, which features the empirically plausible feature that inflation shocks are at least partially accommodated.

$$
m=m_{-1}+\mu+f \varepsilon_{-1}
$$

Without this feature, the price level would be stationary in the model, at odds with the vast body of evidence that price levels have a unit root and that central banks tend to accommodate price level shocks. We could easily include a permanent shock to the money supply, in which case bad news about inflation would be bad news about the exchange rate as in the textbook model. Note that the trend rate of growth in the money supply $\mu$ anchors the trend depreciation in the exchange rate. Finally, we note for future reference that the ex ante real interest rate satisfies by uncovered interest parity $r=q^{e}-q$ with $q=e-p$.

We solve the model for the response of e to an inflation shock. To illustrate our point as simply as possible, we assume that the accommodation parameter $f$ is such that policy accommodates the inflation shock with a one 
period lag, and the model reaches new steady state in one period with $q^{e}=0$. We will solve for the unique $f$ that satisfies this condition, which admits an intuitive interpretation. Interestingly, a more general version of this set up, which allows for gradual accommodation can feature sunspot equilibria. Since the subject of sunspot equilbria with money growth targeting is not the subject of this paper, we stick with the simple example here.

We can re - write the model as

$$
m-p=-\lambda\left(q^{e}-q\right)-\lambda\left(p^{e}-p\right)=\lambda q-\lambda \mu
$$

We have

$$
d p=-\lambda d q
$$

Thus, if an inflation shock causes inflation, the real exchange rate must appreciate under this policy rule. Actual inflation must satisfy

$$
d p=\eta d q+d \varepsilon
$$

Collecting terms, under full accommodation (with a lag of one period)

$$
(1+\eta / \lambda) d p=d \varepsilon
$$

Thus indeed, an inflation shock causes inflation so we know the real exchange rate appreciates. The appreciation dampens the impact of the inflation shock so that inflation rises less than one for one with the inflation shock. Even with ex ante full accommodation, in the period of the shock the money supply is fixed which results in a contraction in demand. Now, what about the nominal exchange rate? Since PPP holds in the long run and policy fully accommodates the shock with a lag, the price level will be permanently higher and thus the exchange rate will be permanently higher (weaker) too. 
There is a presumption that the nominal exchange rate will depreciate on impact. And in fact it almost certainly will in this textbook model. To see this note that

$$
d e=d q+d p=d p(\lambda-1) / \lambda
$$

Now $\lambda$ is the interest semi elasticity of money demand which in empirical studies is usually estimated to be much larger than 1 and in calibration models is often assumed to exceed 5. For example, if the interest elasticity of money demand is 0.5 , then starting from an interest rate if 4 percent, a 1 percentage point rise in the interest rate is a 25 percent increase in that rate and will reduce money demand by 12.5 percent for a semi elasticity of 12.5 Thus there is a presumption that that 'bad news about inflation is bad news about the exchange rate' in a textbook model, both in the long run and on impact in the very short run. Finally note that, for the expectation of full accommodation to be rational the central bank must set

$$
f=(1+\eta / \lambda)
$$

Thus while a policy to accommodate may be chosen freely by the central bank, there is a unique value of the feedback parameter $f$ that insures this is a rational expectation equilibrium. Note also that even though this central bank is a money targeter, an inflation shock will induce the ex ante real interest rate to rise since by UIP, in the period of the shock

$$
d r=-d q=(\lambda+\eta)^{-1} d \varepsilon
$$


Thus a rise in nominal and real interest rates in response to an inflation shock, which is a feature of a stable Taylor rule in a wide variety of models, is also true under money growth targeting with partial accommodation.

\section{Exchange Rate Dynamics Under Open Economy Taylor Rules}

\section{$\underline{4.1 \text { Overview }}$}

In Dornbusch (1976) and Mussa (1982), and in virtually all exchange rate papers written until quite recently - including the 'new open economy' contributions of Obstfeld and Rogoff $(1996,2000)$ and the many other papers recently surveyed and reviewed in Sarno and Taylor (2001) - it is the (stochastic process for) the supply of money which is the key nominal forcing variable for understanding the dynamics of the nominal exchange rate. Although Mussa (1982) in particular allows for a quite general specification of the stochastic process for the money supply, in practice theoretical exchange rate models are almost always solved under quite simple - and counterfactual - restrictions on monetary policy, namely, that the instrument of monetary policy is the stock of money. However, for most of the world's major central banks, the empirical evidence in Clarida, Gali, Gertler (1998) suggests that monetary policy is better described by an interest rate rule of the sort first proposed by Henderson and McKibbon (1990) and Taylor (1993). Recent papers by Engel and West $(2005 ; 2006)$ and by Mark (2004) have begun to explore some of the empirical 
implications for exchange rates if central banks follow Taylor rules for setting interest rates.

The goal of the next two sections is to characterize exchange rate dynamics in a more or less standard open economy model in which the central bank follows an interest rate rule to implement an inflation targeting strategy. The key to solving the model in closed form is to recognize that - as shown in Campbell and Clarida (1987) - if the equilibrium ex ante real interest rate implied by the Taylor rule exhibits first order autoregressive dynamics, then the equilibrium level of the real exchange rate will, period by period, be proportional to the equilibrium ex ante real interest rate. However, the 'constant' of proportionality that links the real exchange rate and the ex ante real interest rate is not a free parameter. Instead, it is a fixed point in the space of expectations for the Markov process which describes the equilibrium inflation process. We show that in this model, conditional on the minimum set of state variables, this fixed point is unique and that the equilibrium is stationary (more precisely, the Blanchard - Kahn (1979) conditions for a unique rational expectations equilibrium are satisfied if the Taylor condition is satisfied).

Some interesting results are obtained. We find that in response to a temporary 'Phillips curve' shock that pushes the inflation rate above target, the nominal exchange rate can either depreciate or appreciate on impact, depending upon how aggressively - as indexed by the Taylor rule slope coefficient on the expected inflation gap - the central bank raises real interest rates to bring inflation back to target. Because of inflation inertia, this adjustment does not 
happen immediately. We find that the equilibrium half-life of an inflation shock (on inflation, output, and the real interest rate) is inversely related to the Taylor Rule coefficient on the inflation gap and is directly related to the Taylor rule coefficient on the output gap. Thus, the more aggressive is the central bank response to an inflation shock, the faster the economy returns to target. However, the more aggressive is the central bank response to the output gap, the slower the economy returns to target

We also examine the dynamic effect of a once and for all permanent reduction in the central bank inflation target. The announcement of a lower inflation target causes the exchange rate to appreciate on impact, inducing a real appreciation and a recession. Inflation falls on impact, but not all the way to target. Along the adjustment path to the new inflation target, the exchange rate is depreciating. Thus, the exchange rate overshoots in response to a 'tightening' of monetary policy.

\section{$\underline{4.2 \text { A Model }}$}

To illustrate the idea as clearly as possible, we will work with the simplest model required. It is a simplified version of the model studied in Svensson (1999). It is comprised of four equations: an aggregate demand equation, an aggregate supply equation, a Taylor rule equation, and an uncovered interest parity equation. The economy is small and takes the world interest rate and world inflation as given and equal to 0 . The aggregate demand equation is given by 


$$
y=-r+(e-p)
$$

where $y$ is log deviation of output from potential, $r=i-E \pi_{+1}$ is the ex ante real interest rate, $e$ is the log nominal exchange rate, and $p$ is the log of the domestic price level. The aggregate supply equation is given by

$$
\pi=\pi_{-1}+y+\varepsilon
$$

where $\pi=p-p_{-1}$ and $\varepsilon$ is a white noise shock to the Phillips curve. Note that we assume a high degree of inflation inertia so that it is the change in inflation is increasing in output gap. This actually will work against the CGG (2002) prediction that under optimal policy 'bad news is good news' since inflation inertia will tend to increase the long run effect on the price level of any given inflation shock. I assume the central bank conducts monetary policy by according to the following Taylor rule

$$
i=E \pi_{+1}+b\left\{\pi-\pi^{*}\right\}+a y
$$

where $\pi^{*}$ is the central bank inflation target and $b$ and $a>0$. Finally, uncovered interest parity implies, in real terms

$$
e-p=E\left\{e_{+1}-p_{+1}\right\}-r
$$

We let $q=e-p$ denote the real exchange rate. Note that $e=\pi+p_{-1}+q$.

We solve equation (17) forward as in Campbell and Clarida (1987) and Svensson (1999) to obtain $q=E \lim _{i \rightarrow \infty} q_{+i}-E \Sigma_{k=0, \infty} r_{+k}$. Thus, the log level of the real exchange rate equals the expected long run equilibrium real exchange rate minus the expected undiscounted sum of short-term real interest rates. In our model the long run log real exchange rate is constant and equal to 0 , so the level of the real exchange rate is given by 


$$
q=-E \Sigma_{k=0, \infty} r_{+k}
$$

We will 'guess' - and later verify - that in equilibrium the ex ante real interest rate follows a zero mean $\mathrm{AR}(1)$ process so that $E r_{+j}=d^{j} r$ with $0<d<$ 1. As shown in Campbell and Clarida (1987), this implies that

$$
q=-r /(1-d) \text {. }
$$

It is sometimes just assumed in models like this (see Ball (1999) for example) that the real exchange rate is proportional to the short-term real interest rate. Although our model has this feature in equilibrium, $d$ is not a 'free' parameter but is in fact a fixed point (and as we will see a function of monetary policy) in the space of expectations for the stochastic process that describes equilibrium inflation.

By substituting (19) into the aggregate demand curve we obtain $y=(2-d) q$. Substituting the Taylor Rule into the real exchange rate equation and using the Phillips curve equation, the system can be written as two equations in two unknowns, $q$ and $\pi$

$$
\begin{aligned}
& q=-b\left(\pi-\pi^{*}\right) /(1-d)-a(2-d) q /(1-d) \\
& \pi=\pi_{-1}+(2-d) q+\varepsilon
\end{aligned}
$$

From (20) we see that $-q\{(1-d)+a(2-d)\}=r\{1+a(2-d) /(1-d)\}=b\left(\pi-\pi^{*}\right)$. Thus, in equilibrium, the ex ante real interest rate is proportional to the inflation gap, even though the central bank also seeks to stabilize output. The dynamics of the system are completely described by the following equation

$$
\pi=\Pi_{-1}-(2-d) b\left(\pi-\pi^{*}\right) /\{(1-d)+a(2-d)\}+\varepsilon
$$


Before moving on, it is useful to pause and understand the logic. To obtain (22), we guessed that the equilibrium ex ante real interest rate follows an $\mathrm{AR}(1)$ process so that $E r_{+j}=d^{j} r$. Equation (22) shows that if this guess is correct, inflation follows an $A R(1)$ process. But, from the Taylor rule, if inflation follows an $A R(1)$ process, then so does the ex ante real interest rate. Thus our guess is not logically inconsistent. However, this logic does not prove that there exists a unique fixed point in the space of expectations over the $A R(1)$ process for r. Collecting terms, we can re-write equation (22) as $\left(\left(\pi-\pi^{*}\right)(1+(2-\right.$ d) $b /\{(1-d)+a(2-d)\})=\left(\pi_{-1}-\pi^{*}\right)+\varepsilon$. It follows that any fixed point in the space of expectations for $r$ must satisfy $(1+(2-d) b /\{(1-d)+a(2-d)\})=1 / d$. The solutions to this equation are just eigenvalues of the dynamic system when written out in Blanchard - Kahn form. It is easy to show that for any $a>0, b>0$ is necessary and sufficient for the existent of a unique rational expectations equilibrium. Figure 1 presents the determination of this unique equilibrium.

Result 1: A rational expectations equilibrium exists, is unique, and is stationary. The equilibrium persistence $d(b, a)$ in inflation and in deviations from purchasing power parity $0<d(b, a)<1$ depends upon the parameters of monetary policy. Persistence is strictly decreasing in $b$ - the Taylor rule coefficient on the inflation gap - and strictly increasing in a - the Taylor rule coefficient on the output gap. 
Thus, for any given Taylor rule coefficients $a \geq 0$ and $b>0$, there is a unique, stationary rational expectations equilibrium. The more aggressively the central bank reacts to the inflation gap (as indexed by the parameter $b$ ), the faster the economy converges to the long run equilibrium, and the less persistent are deviations from PPP. However, the larger the weight placed on output stabilization, (as indexed by the parameter a) the slower the economy converges to the long run equilibrium. Indeed, it is easy to establish the following three limiting cases. First, for any given $a$, as $b \rightarrow 0, d(b, a) \rightarrow 1$. That is, as the weight placed on inflation stabilization goes to zero, inflation and the real exchange rate approach a random walk. Second, for any given $a$, as $b \rightarrow \infty, d$ ( $b$ , a) $\rightarrow 0$. That is, as the weight placed on inflation stabilization goes to infinity, the inflation gap and the real exchange rate approach white noise. Third, for any given $b$, as $a \rightarrow \infty, d(b, a) \rightarrow 1$. That is, as the weight placed on output stabilization goes to infinity, inflation and the real exchange rate approach a random walk.

\section{An Adverse Inflation Shock}

A temporary Phillips curve shock $\varepsilon>0$ pushes up inflation but by less than the shock. This is because the central bank reacts to the inflation shock by pushing up the nominal and the ex ante real interest rate. The real exchange rate appreciates on impact. Output contracts. The effect of a Phillips curve shock on the level of the nominal exchange rate depends upon $b$, the Taylor rule reaction 
parameter to the inflation gap. The following result is easily verified using equation (20) and the fact that $d$ is decreasing in $b$.

Result 2: For any given $a \geq 0$, there exists a $b$ (a) such that, for all $b>b(a)$, $\partial e_{t} / \partial \varepsilon_{t}<0$. That is, if the central bank responds sufficiently aggressively to a rise in inflation, the nominal exchange rate appreciates on impact in response to an adverse inflation shock. For $b<b(a), \partial e_{t} / \partial \varepsilon_{t}>0$.

Thus while the real exchange rate must appreciate in response to an adverse inflation shock, the effect on the nominal exchange rate depends upon the Taylor rule reaction function. Interestingly, the 'inflation nutter' case $a=0$ and $b>0$ is not sufficient to guarantee $\partial e_{t} / \partial \varepsilon_{t}<0$.

The impulse response dynamics to an adverse inflation shock are easy to characterize and are shown in Figures 2 and 3. The nominal interest rate and inflation fall monotonically over time at rate $d$ to $\pi^{*}$, and the output gap and the real exchange rate rise monotonically over time at rate $d$ to 0 . Along the adjustment path, the nominal exchange rate is depreciating at rate equal to the nominal interest rate, until in the steady state it depreciates at the rate $\pi^{*}$.

\section{A Cut in the Inflation Target}

We now consider a once and for cut in the inflation target to $\underline{\Pi}^{*}<\pi^{*}$. In our model, this is assumed to be immediately credible, and to shape expectations on impact. That is, following McCallum, the minimum set of state variables for this model is $s=\left\{\underline{\Pi}^{*}, \varepsilon, \Pi_{-1}\right\}$. As shown above, there is a unique 
rational expectations equilibrium corresponding to this state vector and the parameters $a$ and $b$ which maps $s \rightarrow\left\{\pi, y, q, i, E \pi_{+1}\right\}$. Of course in equilibrium the nominal exchange rate and the price level are non-stationary and are a function of $\left\{\pi^{*}, \varepsilon, \varepsilon_{-1}, \varepsilon_{-2}, \ldots\right\}$.

Assume for concreteness that $\pi_{-1}=\pi^{*}$ and $\varepsilon=0$. In the period in which the inflation target is cut, the equation for inflation in the period of the regime change can be written

$$
\pi=d \pi^{*}+\underline{\pi}^{*}(1-d)
$$

Thus, because of inflation inertia, $0<\partial \pi / \partial \underline{\pi}^{*}<1$ since $d(a, b)<1$ for $b$. It follows that the derivative of the inflation gap with respect to the inflation target is given by $\partial\left(\pi-\underline{\Pi}^{*}\right) / \partial \underline{\Pi}^{*}=-d$. Thus a cut in the inflation target leads to a rise in the inflation gap. By the Taylor rule, the ex ante real interest rate must rise, and thus the real exchange rate must appreciate. As a result, output declines. Indeed it is the induced decline in output that reduces inflation part of the way to $\underline{I}^{*}$. Since inflation falls and the real exchange rate appreciates, the nominal exchange rate must appreciate as well.

We now discuss the impulse response dynamics in periods subsequent to the cut in the inflation target. For concreteness, we focus on the case in which the new inflation target is zero, $\underline{\Pi}^{*}=0$. After the regime change, the nominal interest rate remains above its new steady state level of $i^{S S}=\underline{\pi}^{*}=0$. This is because the inflation gap is positive. Thus, along the adjustment path, the nominal interest rate is everywhere above the world interest rate of $i^{*}=0$, so that 
the nominal exchange rate must depreciating along the adjustment path. In other words

Result 3: In response to a cut in the inflation target, the nominal exchange rate exhibits overshooting. That is, it appreciates on impact and depreciates over time to its new steady state level.

Thus, if the 'surprise' fall in inflation is due to a cut in the inflation target (not a Phillips curve shock), good news for inflation (that it falls) is good news for the exchange rate (it appreciates on impact). Since the model is symmetric, it will also be the case that if a 'surprise' rise in inflation is due to an increase in the inflation target (not a Phillips curve shock), bad news for inflation (that it rises) is bad news for the exchange rate (it depreciates on impact).

\section{$\underline{\text { 5. Empirical Results }}$}

In this section, we use data on inflation announcements and the response of nominal exchange rates around these announcements to empirically test our theoretical model. We focus on three questions: (1) What is the sign of the correlation between inflation surprises and nominal exchange rate changes?; (2) Is it significant?; (3) Is it different for inflation targeters and non-inflation targeters? 
Previewing our results, we find that when we pool the data, bad news about inflation is good news for the exchange rate. The sign of the correlation between inflation surprises and exchange rate changes is positive and statistically significant. When we separate the data into inflation targeters and non-inflation targeters, we find that these results continue to hold for inflation targeting countries, but the coefficients become insignificant for non-inflation targeters.

\section{Data}

Our data set consists of high frequency exchange rate and inflation expectation and announcement data. Below, we describe the construction and properties of our data.

\section{Exchange Rate Data}

Our exchange rate data consists of continuously recorded 5-minute nominal spot data for nine US dollar crosses: USD-JPY, USD-CAD, USD-NOK, USD-SEK, USD-CHF, EUR-USD, GBP-USD, AUD-USD, and NZD-USD. The data, provided by Olsen Associates and Merrill Lynch, begins in July 2001 and ends in December 2005. For GBP-USD and USD-NOK, we also have high frequency exchange rate data covering the periods 1993 to 1996 and 1997 to 2000 , respectively.

We convert the raw spot data to returns, taking 10-minute percentage changes. Although the spot data is recorded at five-minute intervals, we use 10- 
minute changes, since we are interested in exchange rate behavior during the period beginning five minutes before an inflation announcement, and ending five minutes after such an announcement.

Table 1 provides summary statistics for our 10-minute exchange rate return data. For all nine US dollar crosses, the mean 10 -minute return is $0.00 \%$. Although the mean returns are similar across currency pairs, the standard deviations are not, ranging from $0.05 \%$ to $0.09 \%$. The range of standard deviations may be related to the depth and liquidity of markets in different exchange rate crosses. The most liquid currency pairs - USD-JPY, EUR-USD, and USD-CAD - have the lowest standard deviations, and the least liquid crosses - NZD-USD, AUD-USD, USD-NOK, and USD-SEK - have the highest standard deviations.

\section{Inflation Data}

We define an inflation surprise as the difference between the market expectation for an announcement and the announced value of inflation. We arrange the data so that a positive surprise indicates that inflation was higher than expected, while a negative surprise indicates that inflation was announced lower than expected.

For the 2001- 2005 period, our inflation expectations data is from the Bloomberg News Service. Bloomberg surveys commercial and investment banks on their expectations for a wide range of macroeconomic announcements, 
including inflation. We use the median of these expectations as the inflation expectation for a particular announcement.

Our inflation announcement data for 2001- 2005 is from the Bloomberg News Service as well. Bloomberg records and preserves the announced value of macroeconomic variables, in addition to the revised values. This is an important distinction, as macroeconomic data is often revised in the months following its initial release. Since we are concerned only with the immediate response of the exchange rate to an inflation surprise, we need the actually announced data.

In addition to the 2001- 2005 data, we have inflation expectation and announcement data for the UK and Norway for the periods 1993 to 1996 and 1997 to 2000 , respectively. Data for both is provided by Money Market Services, and is similar to the Bloomberg data.

For all countries except the UK, where we use retail prices, we use consumer prices as our inflation metric. For most countries in our sample, expectation and announcement data are available for both headline and core inflation, where core inflation is headline inflation minus some of the volatile components, such as food and energy. We have up to four different measures of inflation for each country in our sample: headline inflation measured as monthover-month and year-over-year changes, and core inflation measured as monthover-month and year-over-year changes.

In Table 2, we present summary statistics for our inflation surprise variables. For most countries in the sample, the mean inflation surprise is slightly 
less than zero, indicating that forecasters have tended to underestimate inflation. However, across all countries and measures of inflation, the absolute value of mean inflation surprises is never greater than 0.1 percentage points, indicating that any potential bias is small. The standard deviations for the inflation surprises are larger than the means, ranging from 0.1 to 0.3 percentage points.

\section{The Model}

We follow the macroeconomic announcement surprise literature, estimating the following equation:

$$
R_{t}=\alpha+\beta S_{t}+u_{t}
$$

Here $R_{t}$ is the ten minute return around the inflation announcement, $S_{t}$ is the inflation surprise, and $u_{t}$ is the error term. The exchange rate return is calculated so that a positive value indicates an appreciation of the local currency, and a negative value represents a depreciation of the local currency. In all tables, the coefficient represents the percentage change in the local currency for a one percentage point surprise in inflation.

\section{All Countries}

Pooling data from all countries in our sample and running a stacked OLS regression on equation 24 , we find that bad news about inflation is indeed good news for the nominal exchange rate. For all four specifications (table 3), the sign on the inflation surprise variable is positive and statistically significant, indicating that higher than expected inflation results in an immediate currency appreciation, 
and that lower than expected inflation results in an immediate currency depreciation. The r-squares from the regressions are substantial, particularly for the specifications using core inflation, where they exceed 0.25 .

Although the signs are positive and significant for all specifications, the results are stronger for the core measures. The coefficients, t-statistics, and rsquares are all larger, with coefficients 2.5 times the size of those in the regressions using headline inflation, and r-squares nearly three times greater. Given the tendency of central banks to focus on core inflation, it is not surprising that markets have reacted more strongly to surprises in this measure.

\section{Inflation Targeters versus non-Inflation Targeters}

Our 10-country sample includes eight inflation targeters and two noninflation targeters - the US and Japan. Our groupings are similar to those used by the IMF, though the IMF does not include the ECB among inflation targeters, as the ECB gives weight to a "reference value" for growth of M3 in the Euro area. Despite this dual mandate, we include the ECB in the inflation targeting group, as it has lessened its emphasis on the M3 reference value in recent years. Including the ECB among the non-inflation targeters would not significantly alter our results.

For our study, the key question is whether or not the sign and significance of $\beta$ are different for inflation targeters and non-inflation targeters. Separating and pooling the data into two categories - inflation targeters and non-inflation targeters - we find significant differences between the two. For non-inflation 
targeting countries, the impact of inflation surprises is not significant, though the estimated sign is generally positive (table 4). For inflation targeters, the estimated coefficients are positive and statistically significant in all four specifications. The r-squares are quite substantial for the inflation targeting regressions, exceeding 0.30 for both core specifications (table 4).

Estimating equation 24 separately for each country confirms these results (table 5). For the two non-inflation targeters, the coefficients are not significant, and for headline inflation in the US are actually of the opposite sign of what the theory predicts. For all eight inflation targeters, the estimated signs are positive, and are statistically significant for six of the countries. These results are particularly strong for the core measures, with r-squares ranging from 0.18 for the UK to 0.65 for Norway.

\section{Regime Changes}

We can also test whether our results hold when there is a clear regime change over time. To test this, we study the granting of independence to the Bank of England in 1997 and the shift to formal inflation targeting in Norway in 2001. For both countries, we have nominal exchange rate and inflation expectation and announcement data prior to and following the regime shifts.

For both countries, the correlation between inflation surprises and nominal exchange rate changes is positive and significant for the 2001- 2005 period, indicating that when central banks in both countries were inflation targeters, bad news about inflation was good news for the exchange rate. However, prior to the 
regime changes in both countries, the estimated coefficients were negative (though not statistically significant), implying that bad news about inflation was bad news for the exchange rate (table 6).

Sign Effects

Finally, we examine whether or not the reaction of the nominal exchange rate differs according to the sign of the surprise. We separate the data into three categories: higher than expected inflation, lower than expected inflation, and as expected inflation. We discard observations where inflation was as expected, and pool the remaining data for all countries into two groups - positive inflation surprises (bad news) and negative inflation surprises (good news). We then estimate equation 24 for both (table 7 ), though we omit the constant in the regression.

Doing so, we find that although the coefficients are positive and statistically significant across all specifications, the effect is stronger for negative inflation surprises (good news) than it is for positive inflation surprises (bad news). The coefficients, t-statistics, and r-squares are substantially higher for the regressions that use negative inflation surprises. Thus, for equivalent inflation surprises, good news will have a larger impact than will bad news.

\section{Concluding Remarks}

In this paper, we have presented what is apparently a new empirical regularity - that for inflation targeting countries, bad news for inflation is good news for the exchange rate. There are two antecedent for this empirical finding 
of which we are aware. The paper by Anderson, et. al. (2003) who report in their tables, but don't discuss, that for some dollar exchange rates during the 1990s inflation surprises and exchange rates covaried in the way reported in this paper, but the estimated effects were not significant. In Goldberg and Klein (2006), it is shown that for most of the sample 1999 - 2005, that bad news about inflation was bad news for the Euro, but that bad news about inflation become good ners for the Euro starting in 2003. They interpret this as consistent with improved ECB credibility during the period. Faust, et. Al. look at 14 years of data for the US and find that bad news about inflation is bad news for the exchange rate. Our findings are also related to but distinct from those in much cited paper by Engel and Frankel (1984) and the paper of Hardouvelis (1984). They looked at the effect of money supply surprises (not inflation surprises) on the exchange rate. They argued that if a money growth targeting regime were credible, then a surprise increase in the money supply - that pushed money growth above target - would be expected to be reversed and that this would cause the nominal exchange rate to appreciate, which is in fact what they found for the Fed and the dollar in the early 1980s. We have presented a simple theoretical model that delivers the prediction that under certain inflation targeting regimes, bad news about inflation can be good news for the exchange rate. This is a 'workhorse' model that does not require the two country dynamic stochastic general equilibrium framework with optimal monetary policy as featured in Clarida, Gali, Gertler (2002), and yet it delivers a similar prediction. What can these results tell us about monetary policy? They suggest two conclusions. First that the 
inflation targeting regimes in the countries featured in our sample are sufficiently credible that they anchor expectations of inflation and the monetary policy path required to achieve the inflation target to such an extent that the currency becomes more valuable upon receipt of news that inflation is surprising high. This credibility effect has to be strong enough to counterbalance the long run PPP anchor which would tend to depreciate the currency on the impact of bad inflation news. We note that this is exactly what we find for the Bank of England before independence and for Norway before the adoption of inflation targeting. A second conclusion is that a credible inflation target is not enough for the "bad news is good news' effect to prevail. In other words, we cannot conclude that if bad news about inflation is bad news for the exchange rate, that a central bank is not an inflation targeter. The central bank must raise interest rates sufficiently aggressively to an inflation shock, and not just greater than one for one as required by the Taylor principle. In particular, this observation is important for correctly interpreting the results for the US and Japan, for which we did not find significant evidence of the 'bad news is good news' effect. Especially in the case of the Fed, we do not interpret our results necessarily as evidence against Fed credibility in anchoring inflation expectations. They are also consistent with the Fed's anchoring those expectations in the context of its dual mandate. 


\section{REFERENCES}

Anderson, T.G., T. Bollerslev, F.X. Diebold and C. Vega (2003): Micro Effects of Macro Announcements: Real-Time Price Discovery in Foreign Exchange, American Economic Review, 93, pp.38-62.

Ball, L.,Policy Rules for Open Economies. In John Taylor (ed.) Monetary Policy Rules, University of Chicago Press, 1999, pp. 127-144.

Blanchard O. and C. M. Kahn (1980), "The Solution of Linear Difference Models under Rational Expectations “, Econometrica 48, pp. 1305-1313.

Campbell, J. \& R. Clarida, 1987, "The Dollar and Real Interest Rates," Carnegie Rochester Conference Series in Public Policy.

Clarida, J. Gali and M. Gertler, "Monetary policy rules in practice: Some international evidence, European Economic Review, 1998, vol. 42, issue 6, pages 1033-1067.

, Optimal Monetary Policy in Open vs. Closed Economies: An Integrated Approach American Economic Review, vol. 91, n² 2, 248-252, 2001

Simple Framework for International Monetary Policy Analysis (with J.

Gali and M. Gertler) Journal of Monetary Economics, vol. 49, $n^{\circ}$ 5, 879-904, 2002

Dornbusch, R., 1976, "Expectations and Exchange Rate Dynamics," Journal of Political Economy, Vol. 84, pp. 1161-76.

Engel, C. and J. Frankel, "Engel, Charles, and Jeffrey A. Frankel, 1984, "Why Interest Rates React to Money Announcements: An Explanation from the Foreign Exchange Market," Journal of Monetary Economics 13, pages 31-39.

Engel, C. and K. West, "Exchange Rates and Fundamentals", Journal of Political Economy, 2005, vol. 113, pp. $485-517$.

Engel, C. and K. West, "Taylor Rules and the Dollar-DM Exchange Rate", Journal of Money, Credit, and Banking, 2006, vol. 38, pp. $1175-1194$.

Faust, J., Rogers, J., Wang, S., and J. Wright, "The High Frequency Response of Exchange Rates and Interest Rates to Macroeconomic Announcements," forthcoming, Journal of Monetary Economics.

Goldberg, L. and M. Klein, "Establishing Credibility: Evolving Perceptions of the European Central Bank," mimeo, NY Fed, March 2006. 
Hardouvelis, G.,"Market Perception of Federal Reserve Policy and the Weekly Money Announcements," Journal of Monetary Economics, 1984, vol. 14, pp. 225-240.

Henderson, D.W. and W.J. McKibbin (1993a), 'A Comparison of Some Basic Monetary Policy Regimes for Open Economies: Implications of Different Degrees of Instrument Adjustment and Wage Persistence', Carnegie-Rochester Conference Series on Public Policy, 39, pp. 221-317.

Mark, N. "Learning Monetary Policy Rules and Exchange-Rate Dynamics," mimeo, University of Notre Dame, 2004.

Mussa, Michael, 1982, "A Model of Exchange Rate Dynamics," Journal of Political Economy, 90 (February), pp. 74-104.

Obstfeld, M. and K. Rogoff, 1996, Foundations of International Macroeconomics (Cambridge, Massachusetts: MIT Press).

2000, "New Directions for Stochastic Open Economy Models," Journal of International Economics 50 (February), pp. 117-53.

Sarno, Lucio and Mark P. Taylor. 2001. Exchange Rate Economics. Cambridge and NY: Cambidge U. Press.

L. Svensson, "Open Economy Inflation Targeting," Journal of International Economics, Vol. 50 (2000): 155-183.

McCallum, Bennett T., "On Non-Uniqueness in Rational Expectations Models: An Attempt at Perspective," Journal of Monetary Economics 11 (March 1983), 139168.

Taylor, John B. 1993. "Discretion Versus Policy Rules in Practice," CarnegieRochester Conference Series on Public Policy, 39, pp. 195-214.

M. Woodford, Interest and Prices, Princeton University Press: 2003. 
Figure 1

Equilibrium as a function of Taylor Rule parameters $b$ and $a$

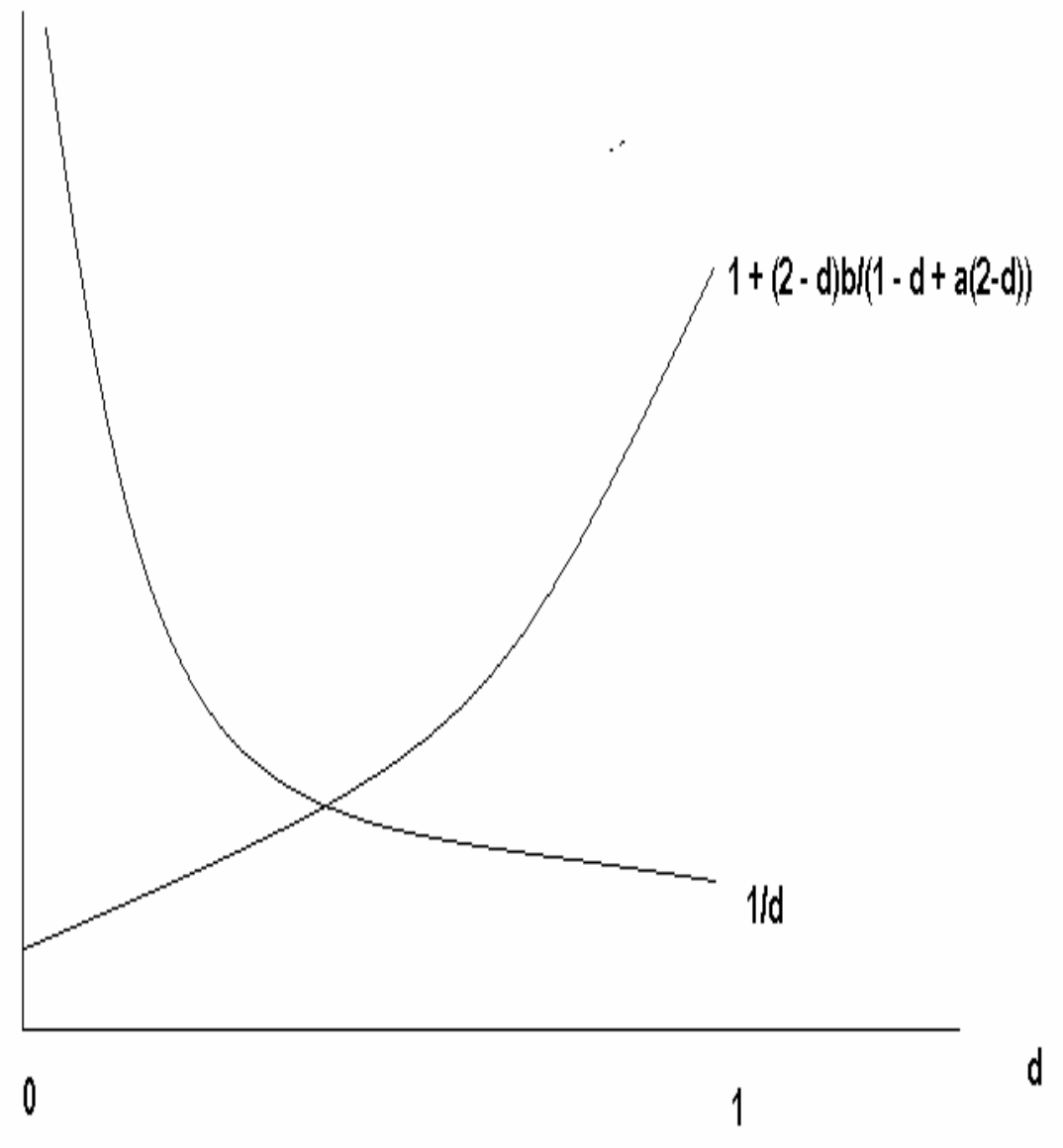


Figure 2

Impulse Response to Inflation Shock - 'Good News' Case $b>b(a)$

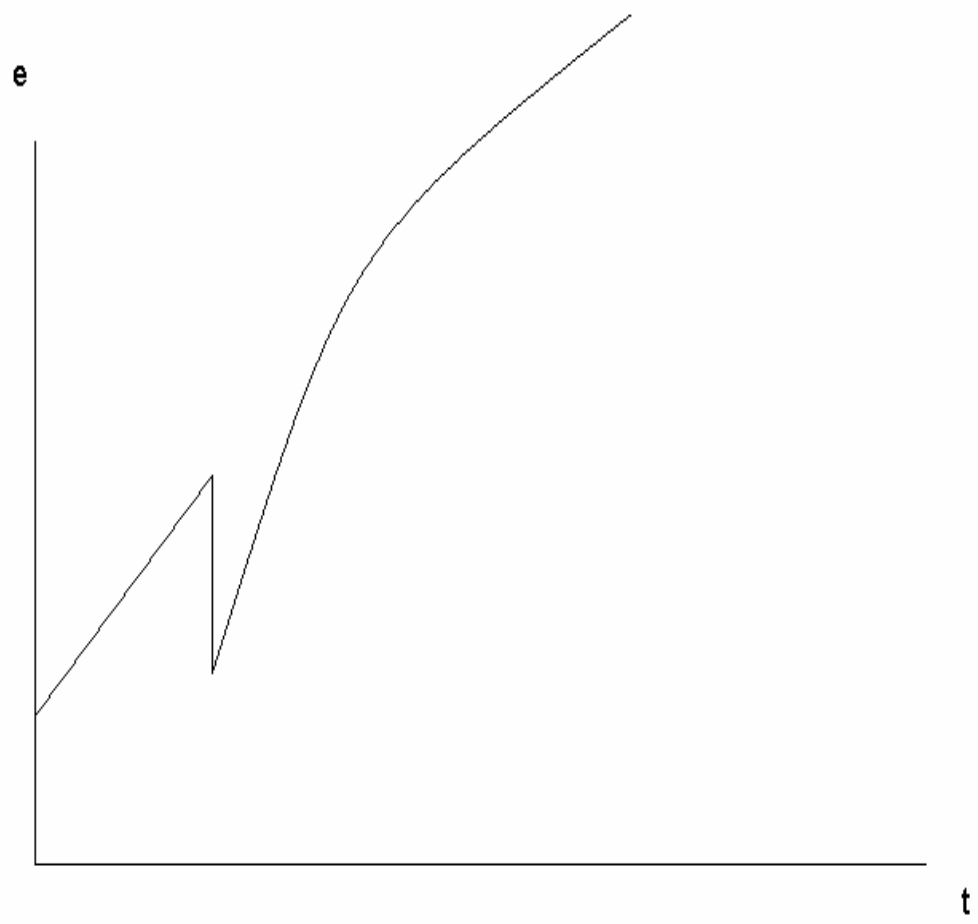


Figure 3

Impulse Response to Inflation Shock - 'Bad News' Case $b<b(a)$

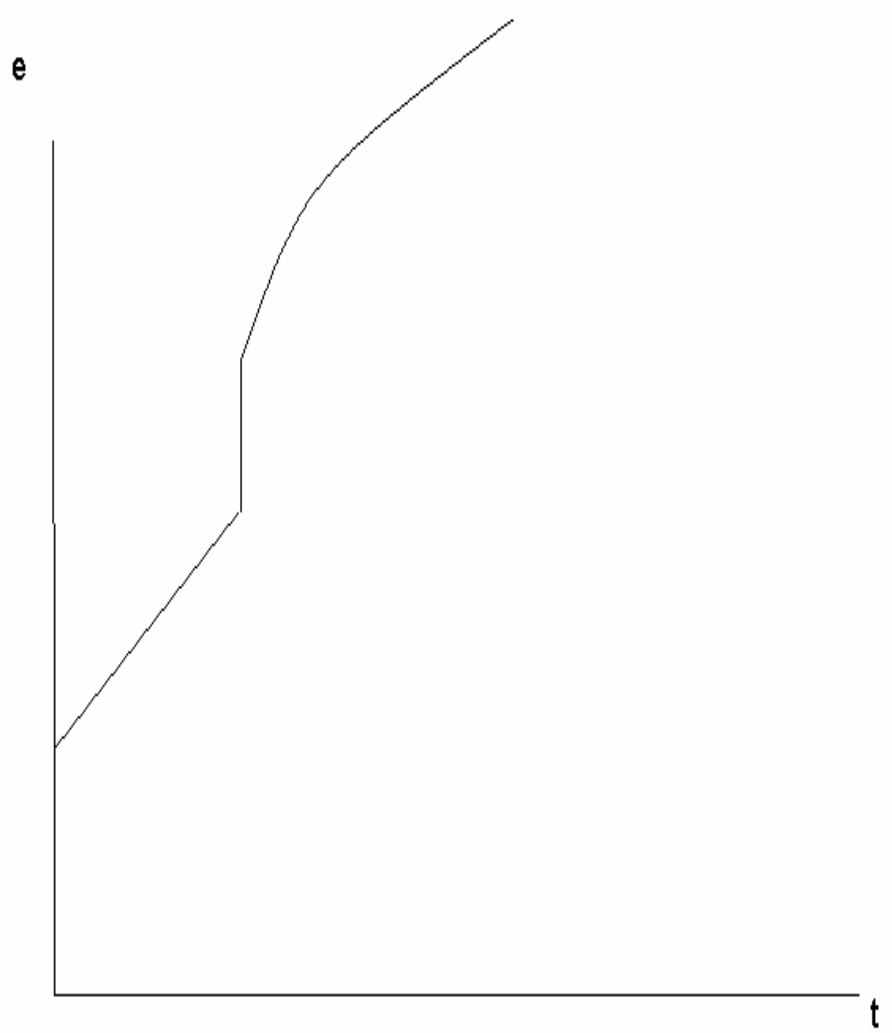


Table 1: 10-Minute Exchange Rate Returns

$\begin{array}{lccc} & \text { AUD-USD } & \text { NZD-USD } & \text { EUR-USD } \\ \text { Mean } & 0.00 \% & 0.00 \% & 0.00 \% \\ \text { Standard Deviation } & 0.07 \% & 0.09 \% & 0.05 \% \\ & \text { GBP-USD } & \text { USD-JPY } & \text { USD-CAD } \\ \text { Mean } & 0.00 \% & 0.00 \% & 0.00 \% \\ \text { Standard Deviation } & 0.05 \% & 0.05 \% & 0.05 \% \\ & & & \text { USD-CHF } \\ \text { Mean } & \text { USD-NOK } & \text { USD-SEK } & 0.00 \% \\ \text { Standard Deviation } & 0.00 \% & 0.00 \% & 0.06 \%\end{array}$

Mean

Standard Deviation

Mean

Standard Deviation

Mean

Standard Deviation

Mean

Standard Deviation

\begin{tabular}{cccc}
\multicolumn{5}{c}{$\begin{array}{c}\text { Table 2: Inflation Surp } \\
\text { Canada }\end{array}$} \\
\multicolumn{3}{c}{ Headline } & \multicolumn{2}{c}{ Core } \\
MoM & YoY & MoM & YoY \\
-0.04 & -0.04 & -0.03 & -0.01 \\
0.21 & 0.23 & 0.15 & 0.17
\end{tabular}

\begin{tabular}{|c|c|c|c|}
\hline \multicolumn{4}{|c|}{ Norway } \\
\hline \multicolumn{2}{|c|}{ Headline } & \multicolumn{2}{|c|}{ Core } \\
\hline MoM & YoY & MoM & YoY \\
\hline-0.07 & -0.09 & -0.09 & -0.10 \\
\hline 0.27 & 0.30 & 0.22 & 0.21 \\
\hline
\end{tabular}

\begin{tabular}{|c|c|c|c|}
\hline \multicolumn{4}{|c|}{ Japan } \\
\hline \multicolumn{2}{|c|}{ Headline } & \multicolumn{2}{|c|}{ Core } \\
\hline MoM & YoY & MoM & YoY \\
\hline 0.03 & 0.02 & 0.02 & 0.02 \\
\hline 0.13 & 0.12 & 0.10 & 0.08 \\
\hline
\end{tabular}

\begin{tabular}{cc}
\multicolumn{2}{c}{\begin{tabular}{c}
\multicolumn{2}{c}{ Australia } \\
Headline
\end{tabular}} \\
QoQ & YoY \\
-0.01 & 0.00 \\
0.18 & 0.19
\end{tabular}

\begin{tabular}{cc}
\multicolumn{2}{c}{ Euro Area } \\
\begin{tabular}{cc}
\multicolumn{2}{c}{ Headline } \\
MoM & YoY \\
0.00 & 0.00 \\
0.09 & 0.07
\end{tabular}
\end{tabular}

\begin{tabular}{cccc}
\multicolumn{2}{c}{ Headline } & \multicolumn{2}{c}{ UK } \\
MoM & YoY & MoM & YoY \\
0.00 & -0.01 & -0.02 & -0.02 \\
0.13 & 0.15 & 0.15 & 0.14
\end{tabular}

\begin{tabular}{cccc}
\multicolumn{2}{c}{ Headline } & \multicolumn{2}{c}{ Sweden } \\
\cline { 3 - 4 } & YoY & MoM & YoY \\
-0.03 & -0.05 & -0.03 & -0.03 \\
0.17 & 0.17 & 0.17 & 0.19
\end{tabular}

\begin{tabular}{cccc}
\multicolumn{2}{c}{ Headline } & \multicolumn{2}{c}{ US } \\
MoM & YoY & MoM & YoY \\
-0.01 & 0.04 & 0.00 & 0.00 \\
0.14 & 0.18 & 0.10 & 0.12
\end{tabular}

\begin{tabular}{c}
$\frac{\text { New Zealand }}{\text { Headline }}$ \\
\hline QoQ \\
-0.04 \\
0.16
\end{tabular}

\begin{tabular}{cc}
\multicolumn{2}{c}{ Switzerland } \\
Moadline \\
MoM & YoY \\
-0.03 & -0.07 \\
0.20 & 0.23
\end{tabular}


Table 3: All Countries

\begin{tabular}{|c|c|c|c|c|}
\hline & \multicolumn{2}{|c|}{$\underline{\text { Headline }}$} & \multicolumn{2}{|c|}{ Core } \\
\hline & МоM & YoY & MoM & YoY \\
\hline Coefficient & 0.2 & 0.2 & 0.5 & 0.5 \\
\hline T- Statistic & 5.9 & 6.2 & 9.7 & 9.2 \\
\hline R-Squared & 0.08 & 0.09 & 0.27 & 0.25 \\
\hline \# Observations & 394 & 387 & 257 & 259 \\
\hline
\end{tabular}

Regression method: stacked OLS.

Percentage change in exchange rate resulting from a one percentage point upward surprise in inflation.

Positive coefficient indicates appreciation of domestic currency.

Countries: Australia, Canada, Euro area, Japan, New Zealand, Norway, Sweden, Switzerland, UK, and US.

Data: July 2001- December 2005. Some countries missing observations.

Table 4: Inflation Targeters versus Non-Inflation Targeters Inflation Targeters

\begin{tabular}{|c|c|c|c|c|c|c|c|c|}
\hline & & \\
\hline & \multicolumn{2}{|c|}{ Headline } & \multicolumn{2}{|c|}{ Core } & \multicolumn{2}{|c|}{ Headline } & \multicolumn{2}{|c|}{ Core } \\
\hline & MoM & YoY & MoM & YoY & МоM & YoY & MoM & YoY \\
\hline Coefficient & 0.3 & 0.2 & 0.6 & 0.5 & 0.01 & -0.08 & 0.1 & 0.1 \\
\hline T- Statistic & 6.1 & 6.7 & 9.4 & 8.9 & 0.2 & -0.8 & 1.3 & 1.1 \\
\hline R-Squared & 0.11 & 0.13 & 0.37 & 0.31 & 0.00 & 0.01 & 0.02 & 0.02 \\
\hline \# Observations & 286 & 310 & 152 & 182 & 108 & 77 & 105 & 77 \\
\hline \multicolumn{9}{|c|}{ Regression method: stacked OLS. } \\
\hline \multirow{2}{*}{\multicolumn{9}{|c|}{$\begin{array}{l}\text { Percentage change in exchange rate resulting from a one percentage point upward surprise in inflation. } \\
\text { Positive coefficient indicates appreciation of domestic currency. }\end{array}$}} \\
\hline & & & & & & & & \\
\hline \multicolumn{9}{|c|}{ Inflation targeters includes: Australia, Canada, Euro area, New Zealand, Norway, Sweden, Switzerland, and UK. } \\
\hline \multicolumn{9}{|c|}{ Non-inflation targeters includes: Japan and US. } \\
\hline Non-inflation targeters & Y include & Japan. & & & & & & \\
\hline
\end{tabular}


Table 5a: Individual Country Results

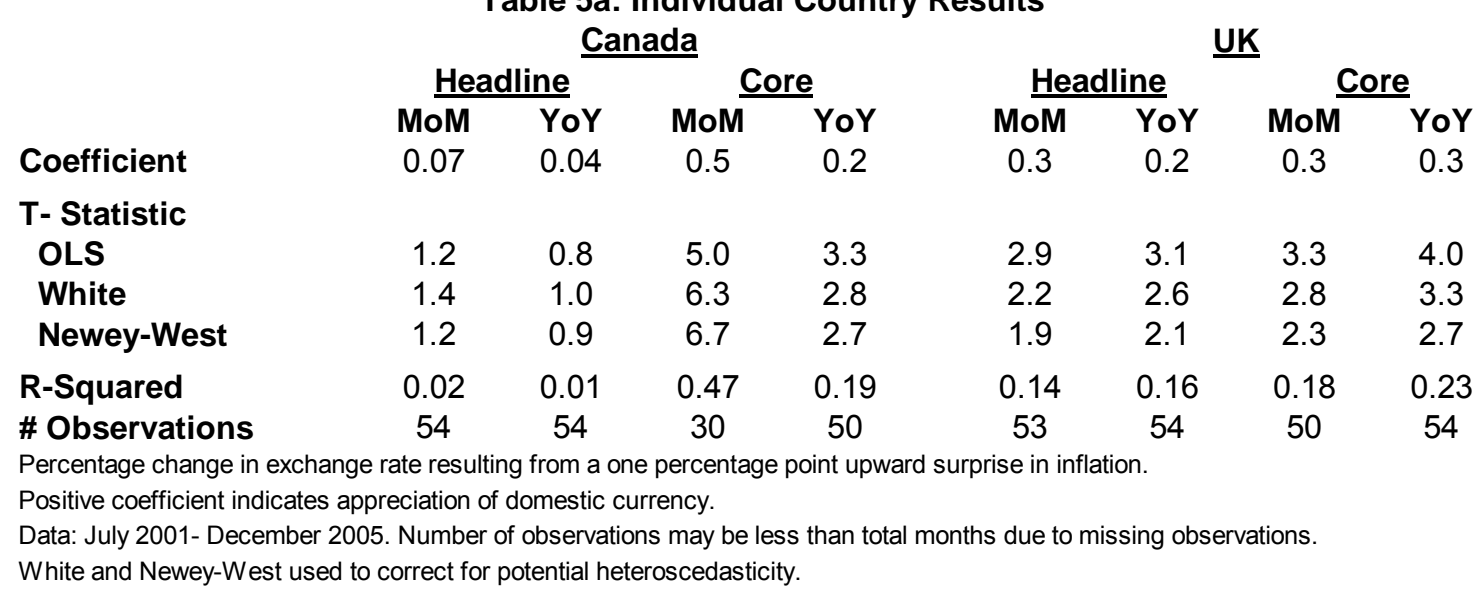

Table 5b: Individual Country Results

Norway

\begin{tabular}{lccccccccc} 
& \multicolumn{2}{c}{ Headline } & \multicolumn{2}{c}{ Core } & \multicolumn{2}{c}{ Headline } & \multicolumn{2}{c}{ Core } \\
Coefficient & MoM & YoY & MoM & YoY & MoM & YoY & MoM & YoY \\
T- Statistic & 0.5 & 0.6 & 1.3 & 1.3 & 0.3 & 0.2 & 0.2 & 0.2 \\
OLS & & & & & & & & \\
White & 2.8 & 3.5 & 7.5 & 7.7 & 3.4 & 3.3 & 3.1 & 3.1 \\
Newey-West & 2.3 & 2.4 & 5.7 & 5.4 & 3.6 & 3.0 & 3.3 & 3.2 \\
R-Squared & 2.0 & 2.1 & 6.6 & 5.7 & 3.4 & 3.1 & 2.9 & 2.9 \\
\# Observations & 0.19 & 0.27 & 0.65 & 0.64 & 0.23 & 0.21 & 0.21 & 0.20 \\
Pb & 35 & 32 & 35 & 41 & 42 & 40 & 42
\end{tabular}

Percentage change in exchange rate resulting from a one percentage point upward surprise in inflation.

Positive coefficient indicates appreciation of domestic currency.

Data: July 2001- December 2005. Number of observations may be less than total months due to missing observations.

White and Newey-West used to correct for potential heteroscedasticity. 
Table 5c: Individual Country Results

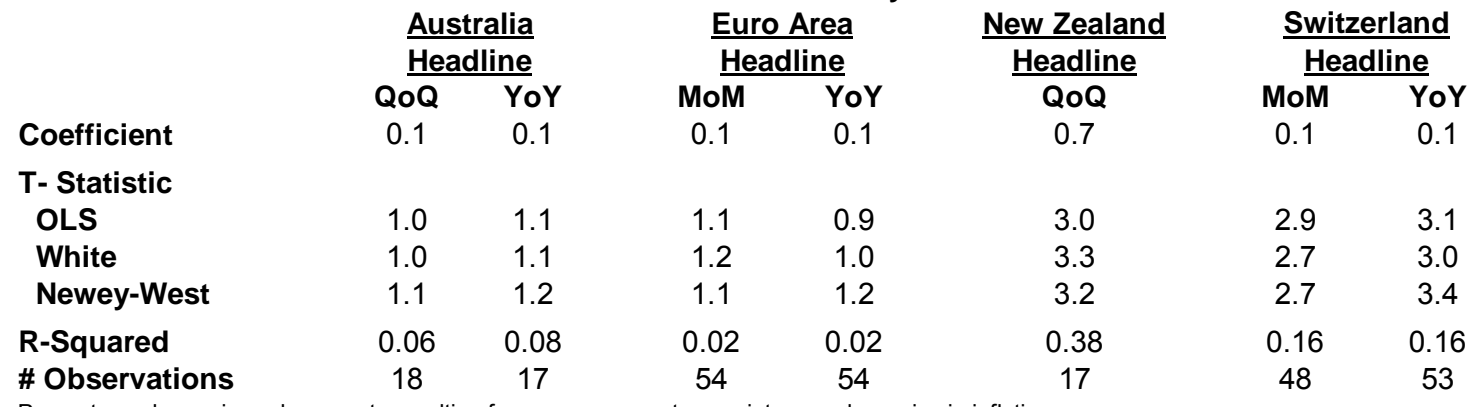

Percentage change in exchange rate resulting from a one percentage point upward surprise in inflation.

Positive coefficient indicates appreciation of domestic currency.

Data: July 2001- December 2005. Number of observations may be less than total months due to missing observations.

White and Newey-West used to correct for potential heteroscedasticity.

Table 5d: Individual Country Results

\begin{tabular}{|c|c|c|c|c|c|c|c|c|}
\hline & \multicolumn{4}{|c|}{ Japan } & \multicolumn{4}{|c|}{$\underline{\text { US }}$} \\
\hline & \multicolumn{2}{|c|}{ Headline } & \multicolumn{2}{|c|}{ Core } & \multicolumn{2}{|c|}{ Headline } & \multicolumn{2}{|c|}{ Core } \\
\hline & MoM & YoY & MoM & YoY & MoM & YoY & MoM & YoY \\
\hline Coefficient & 0.07 & 0.1 & 0.07 & 0.07 & -0.1 & -0.2 & 0.1 & 0.2 \\
\hline T- Statistic & & & & & & & & \\
\hline OLS & 1.4 & 1.8 & 1.0 & 0.7 & -0.4 & -1.1 & 0.9 & 0.7 \\
\hline White & 1.2 & 1.9 & 0.8 & 0.7 & -0.4 & -1.1 & 0.9 & 0.7 \\
\hline Newey-West & 1.3 & 1.6 & 0.7 & 0.7 & -0.4 & -1.2 & 0.9 & 0.8 \\
\hline $\begin{array}{l}\text { R-Squared } \\
\text { \# Observations }\end{array}$ & $\begin{array}{c}0.04 \\
54\end{array}$ & $\begin{array}{c}0.06 \\
54\end{array}$ & $\begin{array}{c}0.02 \\
51\end{array}$ & $\begin{array}{c}0.01 \\
52\end{array}$ & $\begin{array}{c}0.00 \\
54\end{array}$ & $\begin{array}{c}0.05 \\
25\end{array}$ & $\begin{array}{c}0.01 \\
54\end{array}$ & $\begin{array}{c}0.02 \\
25\end{array}$ \\
\hline
\end{tabular}

Percentage change in exchange rate resulting from a one percentage point upward surprise in inflation.

Positive coefficient indicates appreciation of domestic currency.

Data: July 2001- December 2005. Number of observations may be less than total months due to missing observations.

White and Newey-West used to correct for potential heteroscedasticity. 
Table 6: UK and Norway Pre-Inflation Targeting

\begin{tabular}{|c|c|c|c|}
\hline \multicolumn{3}{|c|}{ UK } & Norway \\
\hline & & Core & Headline \\
\hline MoM & YoY & $\overline{\text { YoY }}$ & YoY \\
\hline 0.006 & -0.05 & -0.06 & -0.08 \\
\hline
\end{tabular}

\section{T- Statistic}

$\begin{array}{lcccc}\text { OLS } & 0.1 & -0.5 & -0.7 & -1.0 \\ \text { White } & 0.1 & -0.7 & -0.8 & -1.6 \\ \text { Newey-West } & 0.1 & -1.1 & -1.4 & -1.6 \\ \text { R-Squared } & 0.00 & 0.01 & 0.01 & 0.02 \\ \text { \# Observations } & 46 & 46 & 46 & 40\end{array}$

Percentage change in exchange rate resulting from a one percentage point upward surprise in inflation.

Positive coefficient indicates appreciation of domestic currency.

Dates: Norway: August 1997- December 2000. UK: March 1993- December 1996.

Number of observations may be less than total months due to missing observations.

White and Newey-West used to correct for potential heteroscedasticity.

Table 7: Good News Versus Bad News

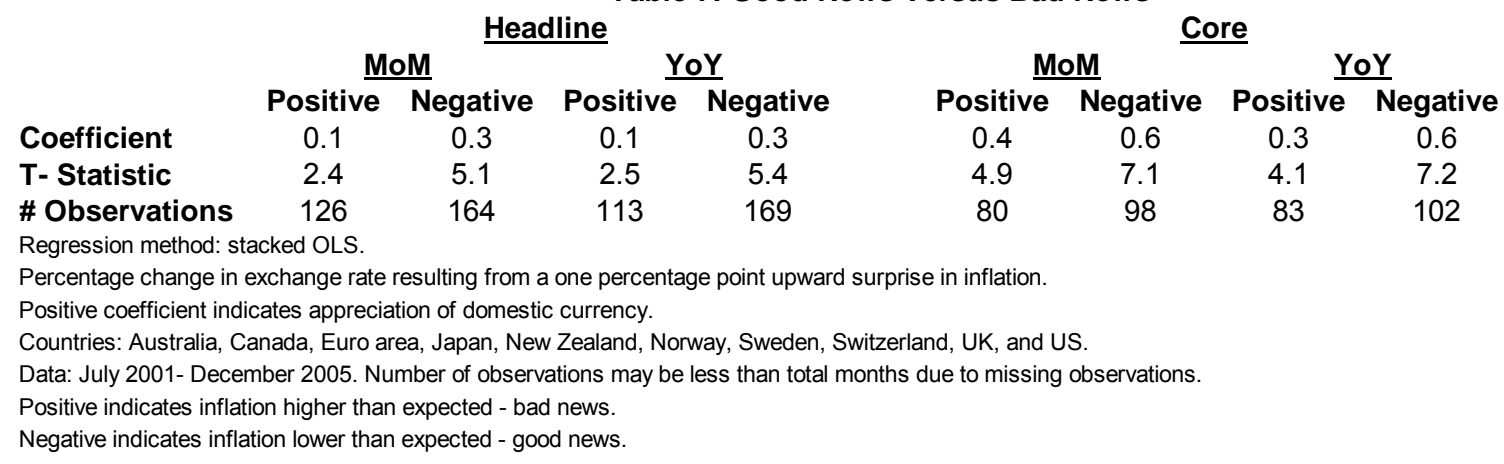


The end 